\title{
METÁFORA, FUTEBOL E VIOLÊNCIA EM MINAS GERAIS
}

\author{
Luciane Corrêa Ferreira ${ }^{1}$
}

\section{RESUMO}

Este artigo apresenta a linguagem metafórica, assim como metonímica, que surgiu em interações discursivas entre os participantes da pesquisa, quando conversaram sobre a convivência com a violência no futebol em Minas Gerais. Utilizamos uma abordagem da metáfora à luz da dinâmica do discurso que sustenta que as metáforas utilizadas pelas pessoas na fala refletem suas emoções, valores e opiniões. A análise foi centrada em dados coletados a partir da discussão em um grupo focal em Belo Horizonte, Minas Gerais, Brasil. Nossa pergunta de pesquisa foi: de que maneira os participantes usam linguagem figurada quando falam sobre violência no futebol? Adotamos a análise do discurso à luz das metáforas (CAMERON et al., 2009) que nos permite refletir sobre a maneira como os brasileiros enfrentam situações de violência urbana e sobre a linguagem figurada que eles usam para conceitualizar a violência.

Palavras-chave: Violência urbana. Futebol. Linguagem figurada. Metáfora.

\section{FUTEBOL E METÁFORA: ESTUDOS PRECURSORES}

Em um estudo realizado anteriormente, buscou-se investigar expressões metafóricas motivadas pelo domínio experiencial futebol na mídia mineira. Objetivou-se discutir que domínios experienciais fonte vão mapear o domínio-alvo futebol e viceversa (FERREIRA, submetido). Veja-se o exemplo a seguir:

(1) "Confronto direto/As armas de cada um." (Estado de Minas, Super Esportes, 28/08/2011, p. 4) 
(2) "Atlético e Cruzeiro se enfrentam hoje, às 18h, na Arena do Jacaré, em Sete Lagoas, pela 19a. rodada, buscando a redenção." (Estado de Minas, Super Esportes, 28/08/2011, p. 4)

Note-se que varias fases da GUERRA se refletem no discurso sobre o futebol, desde 'preparar as armas' que seria a preparação para o 'confronto' até o 'embate' e, por fim, a 'redenção'. Tratam-se de evidências que parecem atestar a existência de um domínio FUTEBOL bastante bem delineado. A arena onde ocorre o jogo de futebol é decorada com escudos e bandeiras, e lá se ouvem hinos e 'gritos de guerra' das torcidas. Algumas torcidas chegam mesmo a levar nomes como 'Exército Gremista' e 'Pavilhão 9', torcidas respectivamente dos times Grêmio de Porto Alegre e Corinthians de São Paulo, que aludem claramente à prisão e ao domínio militar.

Tal riqueza de dados discursivos possibilita ter uma idéia dos diferentes facetas do domínio GUERRA, ressaltando aspectos a partir dos quais o futebol é percebido por meio de metáforas de semelhança (GRADY, 1997), por exemplo, a partir de metáforas discursivas como 'comando','armas', 'confronto', 'rival' e outras que aparecem nas reportagens da mídia brasileira sobre futebol.

Os resultados desse estudo apontaram mapeamentos metafóricos que contemplaram os domínios experienciais fonte ARTE, GUERRA, RELIGIÃO, NEGÓCIO, EDIFÍCIO, utilizados para falar sobre o domínio-alvo FUTEBOL e o uso do esquema imagético de CONTÊINER (FERREIRA, 2011). Em um estudo comparativo sobre metáforas utilizadas para se falar de futebol no Brasil e na Alemanha (FERREIRA; GONÇALVES, 2011), constatou-se que a imprensa escrita alemã utiliza metáforas do domínio ARTE para referir a maneira dos jogadores jogarem, falando em mágica.

Estudos apontam que expressões metafóricas para descrever esportes e jogos frequentemente são motivadas pelos domínios experienciais ARTE, GUERRA, RELIGIÃO E VIOLÊNCIA (SIMÓ, 2008). Por exemplo, quando um repórter afirma que "a torcida não conseguia ver sangue durante o jogo" ${ }^{2}$, o domínio experiencial VIOLÊNCIA é ativado a fim de descrever a experiência abstrata de sofrimento envolvida quando os fãs assistem a um jogo de futebol. Simó (2008) distingue entre o domínio 
experiencial VIOLÊNCIA E GUERRA na conceitualização do jogo de xadrez, pois a autora argumenta que nem todas as expressões do domínio experiencial GUERRA, utilizadas para falar do esporte, são violentas, mas sim se referem à estratégia. $O$ mesmo se aplica ao futebol, pois falamos de tática, ataque e defesa em futebol, e tais conceitos não estão necessariamente relacionados a atitudes violentas no campo.

Já que o futebol é considerado uma metáfora da sociedade e uma representação da vida social, a violência presente na sociedade brasileira tem se refletido também nos campos. O futebol - e os esportes em geral - são frequentemente descritos na Sociologia como rituais de violência simbólica com um objetivo civilizatório (ELIAS, 1994) por desestimularem a violência direta. A manifestação dessa violência seria sempre acionada por um fato que serve como estímulo externo, como a impunidade, o descaso das autoridades e de políticas públicas, assim como por uma estreita relação com outras questões referentes à agressividade direta, como tráfico de drogas, xenofobia e racismo, ou indireta, como pobreza e exclusão social.

Portanto, o futebol não é violento, embora historicamente esteja associado a rituais de guerra e isso se reflita na linguagem utilizada para falar de e descrever o futebol, em que encontramos termos empregados no domínio experiencial GUERRA, como 'tática', 'ataque', 'defesa', entre outros. Os exemplos de violência no futebol que chamam mais atenção acontecem fora de campo e estão relacionados à atuação das torcidas organizadas no Brasil e ao fenômeno do hooliganismo na Europa. Embora um índice de violência de 5\% (MURAD, 2007, p. 21) no futebol brasileiro seja considerado problemático, a mídia sensacionalista faz com que a sensação de insegurança com relação à ida do espectador brasileiro aos estádios de futebol aumente. Infelizmente, segundo constata Murad (2012, p. 37), entre 1999 e 2008 houve 42 mortes de torcedores, contabilizando 4,2 mortes de torcedores por ano. Também segundo Murad (2012), tal número de mortes subiu para 12 torcedores mortos por ano em 2010. Mais chocante ainda é saber que $78,8 \%$ das mortes são de torcedores sem nenhuma ligação com grupos de torcidas organizadas (MURAD, 2012, p. 38). Tal insegurança também se reflete no discurso dos participantes do presente estudo, frequentadores de estádios e amantes do futebol. 
Assim como Murad, acredita-se que a violência no futebol apenas reflete a violência presente na sociedade brasileira como um todo. Por isso mesmo, ao realizarmos um estudo precursor sobre metáfora e violência urbana em Belo Horizonte (FELTES; PELOSI; FERREIRA, 2012), o medo da violência no futebol foi mencionado pelos participantes durante as discussões no grupo focal.

Vejamos como os participantes discutem sobre o que pode ocorrer no futuro com relação à violência no futebol:

\section{Excerto 1:}

614. Bárbara: Mas as "UPPS" é porque a Copa ta chegando

615. São todas ao redor dos estádios..

616. combater a violência pela Copa

617. Bruno: Sim, é tudo interesse..

618. é tudo interesse..

619. Bárbara: Acho que eles só começam a se preocupar quando ta atingindo eles..

620. Bruno: Bom ou não..

621. aposto que quem ta na região achou uma beleza..

622. com certeza não é o ideal..

623. Bárbara: Mas não foi feito por causa da violência..

624. é porque a gente tem que estar bonitinho pra Copa.

Verificou-se como o participante utiliza esquemas imagéticos (FONTECAMINHO-META) e a imagem da violência no futebol como uma progressão em um contínuo, como se fosse um deslocamento linear em uma trajetória (linha 614, veja-se a personificação da Copa e a idéia mencionada de 'estar chegando'). Detexta-se aqui também o que Cameron (2010) chama de 'metáfora da paisagem', em que o participante atribui a uma região (linha 621), um lugar (estádio, I. 615) uma outra significação. Nesse caso, a região referida é o entorno do estádio conhecido como Maracanã, localizado no Rio de Janeiro, sede da final da Copa Fifa 2014, que recebeu uma Unidade de Polícia Pacificadora (UPP) e está passando por uma serie de modificações do entorno em função de medidas preventivas de segurança para a Copa. 
Na linha 624, a participante Bárbara reforça uma 'estória circulante' na opinião da população brasileira sobre a Copa da Fifa 2014 quando afirma "é porque a gente tem que estar bonitinho pra Copa". Nesse evento discursivo, "estar bonitinho pra Copa" é uma metáfora sistemática recorrente nas interações dos participantes no grupo focal que representa uma estabilização no discurso sobre a realização de tal evento no Brasil. A metáfora sistemática é MEDO DA VIOLÊNCIA É DESEMPENHAR PAPEIS ${ }^{3} \mathrm{e}$ trata-se de uma metáfora recorrente também nos dados coletados em Belo Horizonte sobre violência urbana, reforçando uma possibilidade arrolada por Cameron de que uma metáfora sistemática não é exclusiva de um evento discursivo, mas pode aparecer em mais de um evento discursivo (CAMERON, LOW E MASLEN, 2010, p. 125). Podese verificar, a partir dos exemplos de metáforas e metonímias arrolados nesses exemplos, como a fala dos participantes é muito rica em imagens que descrevem figurativamente seus medos com relação à violência experienciada no futebol.

A seguir discutiremos a violência no futebol como emergiu nas metáforas e metonímias discursivas utilizadas pelos participantes na discussão com o grupo focal em Belo Horizonte.

\section{FUTEBOL E A METÁFORA DISCURSIVA}

Cameron (2003) sugere que, para se compreender a metáfora, é necessário entendê-la no seu uso dialógico como parte integrante do uso da língua, como propõe Bakhtin. A língua é aqui entendida como sistema dinâmico complexo, assim, nas interações, o fluxo discursivo ocorre como um processo de "pensamento-e-fala", em que $o$ uso de hífens na expressão sinaliza a estreita relação entre pensamento e linguagem. "Pensamento-e-fala" é um processo dinâmico e dialógico que exige a coconstrução situada por parte dos participantes da palavra do outro e a sua adaptação, a partir dessa compreensão, na proporção que intenções e emoções evoluem no fluxo do discurso. Dessa forma, cognição e linguagem seriam indissociáveis. As metáforas que emergem no discurso fazem parte de um processo dinâmico em constante mudança, motivado por fatores cognitivos, contextualmente e socioculturalmente situados, assim como fatores linguísticos. Objetivamos, assim, 
partindo-se do discurso produzido por vítimas diretas ou indiretas de violência no futebol em uma discussão com um grupo focal, verificar a emergência e constituição de expressões figuradas para conceitualizar a violência no futebol.

O método de análise do discurso à luz das metáforas trabalha com linguagem metafórica, especificamente, com veículos metafóricos (CAMERON, 2010) emergentes no discurso. Após a transcrição das gravações com auxílio do software Atlas.ti, as metáforas linguísticas são identificadas e codificadas. Em seguida, padrões de sistematicidade são identificados e examinados. Estudos realizados anteriormente apontaram para $\mathrm{o}$ fato de que as metáforas utilizadas pelos falantes revelam informações úteis sobre suas idéias, atitudes e valores. Por exemplo, o estudo de Cameron (2003) apontou que as metáforas utilizadas em interações em sala de aula revelam atitudes e expectativas de alunos frente ao processo de aprendizagem e possibilitam aos alunos outras maneiras de falar sobre os conteúdos aprendidos. Busca-se identificar metáforas sistemáticas no discurso que são como um fio encadeador na interação, sendo utilizadas e retomadas várias vezes pelos participantes do grupo focal. A metáfora sistemática configura-se como uma estabilização temporária no discurso e aparecerá nas análises em itálico.

Cameron (2008) mostrou como metáforas em conversas de reconciliação desvelam idéias chave e mudam as atitudes dos participantes, conforme o processo de reconciliação evolui por meio de deslocamentos metafóricos, i.e. deslocamento do veículo (vehicle re-deployment), desenvolvimento do veículo e literalização do veículo (p. 61).

O discurso metafórico e o não metafórico se interconectam na concretização de objetivos discursivos, ao passo que as metáforas mudam na fala dos próprios participantes e entre participantes nas interações. Cada instanciação metafórica está fortemente encaixada no seu contexto discursivo imediato. À medida que se identificam, no fluxo da conversa, padrões no uso de metáforas, identifica-se os tópicos discursivos e, a partir daí, tem-se subsídios para a identificação das metáforas sistemáticas no discurso. O processo de listagem e separação das metáforas destaca o papel do contexto. 
Este estudo foi desenvolvido em colaboração com o projeto Metáfora e a constante ameaça de violência urbana no Brasil, coordenado pela Profa. Ana Cristina Pelosi em Fortaleza, Ceará, e do qual participam ainda professores da UCS e da UFMG. O projeto guarda-chuva é coordenado pela Profa. Lynne Cameron da Open University, Milton Keynes, Reino Unido e investiga como a linguagem figurada é empregada na interação para se falar de atos terroristas, sendo também objetivo do projeto comparar os dados sobre terrorismo com os dados sobre violência urbana no Brasil. No presente estudo, investigamos como participantes de um grupo focal falam sobre sua experiência com violência no futebol e seus sentimentos quanto ao tema como pessoas que vivenciam o futebol em Minas Gerais como torcedores de clubes mineiros. Silva (2013) investiga a violência no futebol do Ceará utilizando a mesma metodologia e com o mesmo objetivo, em que torcedores dos dois maiores clubes cearenses, Fortaleza e Ceará, participam de uma discussão em grupo focal. Há muitos paralelos entre os resultados dos dois estudos com torcedores de Minas Gerais e do Ceará.

O risco de violência urbana no Brasil é contínuo. Infelizmente tais riscos também se referem à violência no esporte. Cameron fala em "estórias circulantes" (circulating stories) que são eventos significativos que se transformam em estórias compartilhadas, por exemplo, o caso dos torcedores do Corinthians na Bolívia, o caso do torcedor do Cruzeiro morto por membros da Galoucura na região central de Belo Horizonte ${ }^{4}$ e o caso do goleiro Bruno 5 .

Em um estudo anterior com grupo focal (FERREIRA, 2012), buscamos mostrar como o nome da torcida de um clube de futebol da capital mineira é mencionado por uma participante com um uso metonímico em uma interação em que os participantes relatam a sua experiência com violência urbana na cidade de Belo Horizonte. Veja no excerto a seguir como a participante Patrícia utiliza uma metonímia sistemática que veicula a imagem de um CONTÊINER (DENTRO/ FORA) para referir a sensação de proteção por pertencer a um grupo, i.e. o sentimento de estar DENTRO, no caso dentro do grupo da torcida da Galoucura: 


\section{Excerto 2:}

Patrícia: Teve uma vez que o cara tentou me assaltar,

aí eu virei pra ele

$<$. qual é rapaz, aqui é galoucura

..cê vai mexer comigo, cê é doido?> [riso]

..aí ele saiu correndo, velho

saiu correndo de mim!

..Ele ficou com o maior medo

Bruno: ...Nó e eu passo mesmo

..não to nem $f$

..morrer de graça não

Patrícia: ..Eu já tô muito experiente em assalto

..já fui assaltada sete vezes

..da última eu falei

..da última eu fui esperta, meu filho, agora

agora eu sei que eu sou da galoucura [risos]

agora ninguém me assalta mais não.

(FERREIRA, 2012, p.174-175)

Na fala de Patrícia, Galoucura funciona como uma metonímia NOME pela AÇÃO, em que o nome Galoucura é automaticamente identificado com as ações violentas perpetradas por membros da torcida Galoucura. Ao proferir "aqui é Galoucura", Patrícia aciona intencionalmente a inferência de que, se o agente de violência causar algum dano a ela, estará agindo contra a torcida, estabelecendo uma relação metonímica de PARTE-TODO. Ao falar "agora eu sei que eu sou da Galoucura", Patrícia também aciona a possível inferência de que inventou que é membro da Galoucura para motivar o sentimento de medo no seu interlocutor, o ladrão que iria assaltá-la. O submodelo com propriedades comuns que reúne semelhanças de família para configurar a categoria VIOLÊNCIA é o que congrega as propriedades AGENTE PERCEPTÍVEL, AÇÃO DIRETA, EMPREGO DA FORÇA FÍSICA e DANO MATERIAL (FELTES, 2007, 
p. 263), enfim algumas propriedades relacionadas com atividades com as quais a imagem da torcida Galoucura está relacionada.

\section{METODOLOGIA}

Este é um estudo de natureza qualitativa. Seguimos os procedimentos metodológicos descritos em Cameron et al (2009). Onze participantes, estudantes de graduação na Universidade Federal de Minas Gerais (UFMG), participaram da coleta de dados em um grupo focal em outubro de 2012. A fim de promover a interação entre os participantes do grupo focal, um membro do grupo de pesquisa atuou como moderador da discussão. Foram adotados pseudônimos na transcrição, a fim de preservar a identidade dos participantes.

Os dados foram coletados por meio de entrevistas semi-estruturadas. Procedeuse a uma análise do discurso guiada por metáforas (Cameron et al., 2009), tendo os dados sido transcritos (13.880 palavras) com o apoio do software Atlas.ti de análise qualitativa. Os dados foram posteriormente codificados em metáforas, metonímias, tópicos discursivos e cenários, a fim de facilitar a identificação de metáforas sistemáticas na dinâmica do discurso. Metáforas individuais foram reunidas em grupos de metáforas para se identificar padrões sistemáticos. Em primeiro lugar, os Tópicos Discursivos (TDs) foram identificados, por exemplo, tópicos como 'pessoas', 'violência', 'mídia', 'autoridades', 'local', cf. Cameron (2010). A identificação dos TDs nos auxiliou a localizar os veículos metafóricos. Então, os veículos metafóricos foram identificados e agrupados. A identificação dos veículos metafóricos deu-se cf. uma versão adaptada do PIM ou MIP (Metaphor Identification Procedure) adotado pelo Grupo Pragglejaz (2007), que considera metafórico qualquer uso incongruente ou diferente de um termo que difere do seu significado mais concreto. Tal adaptação teve que ser feita porque o PIM trabalha a partir da identificação de palavras incongruentes, e não de veículos metafóricos, como é o caso dos dados desse estudo. Veículos metafóricos e metonímias foram identificados e codificados. Por exemplo, palavras ou expressões referentes à 'mídia' foram agrupadas, expressões relativas à 'localização' usadas com valor metonímico foram agrupadas, por exemplo 'estádio' e 'rua'. 
O método de análise do discurso à luz das metáforas (CAMERON et al., 2009) opera a partir de uma análise que não é indutiva, de baixo para cima (bottom-up), baseada numa abordagem que desconsidera a possibilidade da existência de metáforas conceituais; nem dedutiva, de cima para baixo (top-down), partindo da premissa de que cada instância de metáfora na interação seria uma expressão linguística licenciada por metáforas conceituais. Trata-se de um processo interativo e recursivo que vai dos dados resultantes da interação no grupo focal ao contexto social maior (MACEDO, 2010). Foram adotados os seguintes procedimentos metodológicos na análise dos dados:

1. adaptação do questionário de Cameron (2006), traduzido pelos membros do Grupo de Pesquisa GELP 6 / COLIN da Universidade Federal do Ceará para investigar violência urbana no Brasil, com o objetivo específico de abordar no grupo focal a violência no futebol (FERREIRA, 2011);

2. coleta de dados com um grupo focal ${ }^{7}$ com onze participantes em outubro de 2012;

3. transcrição dos dados coletados com o auxílio do software Atlas.ti;

4. análise dos dados.

Trabalhamos com corpora oriundos da gravação e filmagem de um grupo focal, buscando identificar e analisar metáforas recorrentes em seus discursos para sentimentos de agressividade e/ou outras noções referentes a situações de violência experimentadas por adultos, vítimas diretas ou indiretas de violência urbana. Os informantes foram selecionados entre frequentadores de cursos acadêmicos em nível de graduação da Universidade Federal de Minas Gerais, na faixa etária entre 18 e 40 anos. Onze pessoas participaram da pesquisa, sendo sete mulheres e quatro homens. Os nomes dos participantes foram modificados para pseudônimos, a fim de preservar o sigilo de sua identidade. A participação de cada informante foi voluntária e todos os participantes assinaram um Termo de Consentimento Livre e Esclarecido concordando em participar da pesquisa ${ }^{8}$. A duração máxima do período de discussão em grupo foi de 80 minutos. Treze perguntas foram lançadas uma a uma para o grupo conforme 
procedimentos previamente adotados quando da coleta de dados para o projeto sobre metáfora e violência urbana em Minas Gerais (FERREIRA, 2012). As discussões foram filmadas e transcritas para análise. Identificamos nas interações os tópicos discursivos, narrativas, veículos metafóricos, metáforas e metonímias sistemáticas referentes à conceitualização da violência no futebol, nosso objeto de estudo. Os dados foram codificados para identificar as metáforas e metonímias, assim como narrativas pessoais e cenários. Metáforas individuais foram agrupadas para se encontrar padrões sistemáticos de metáforas. Também foi realizada uma análise das metáforas conceituais (LAKOFF; JOHNSON, 1980) e dos esquemas imagéticos, por exemplo, FONTE-CAMINHO-META e CONTENIMENTO (JOHNSON, 1987) observados nos dados, isto é, os elementos cognitivos identificados nos dados, o que nos auxiliou a entender as motivações cognitivas nas interações discursivas.

Resultados apontam para os seguintes tópicos discursivos nas interações do grupo focal analisado (FERREIRA, 2013):

-Emoções

-Estrutura do futebol no Brasil

- Fazer parte de um grupo

-Futebol no exterior

-Mídia

-Mudança

-Política •Educação

-Atitudes dos jogadores

-Autoridades

- Comparação com outros esportes

- Grupos afetados pela violência

-Respeito

•Violência 
FIGURA 1 - Tópicos Discursivos

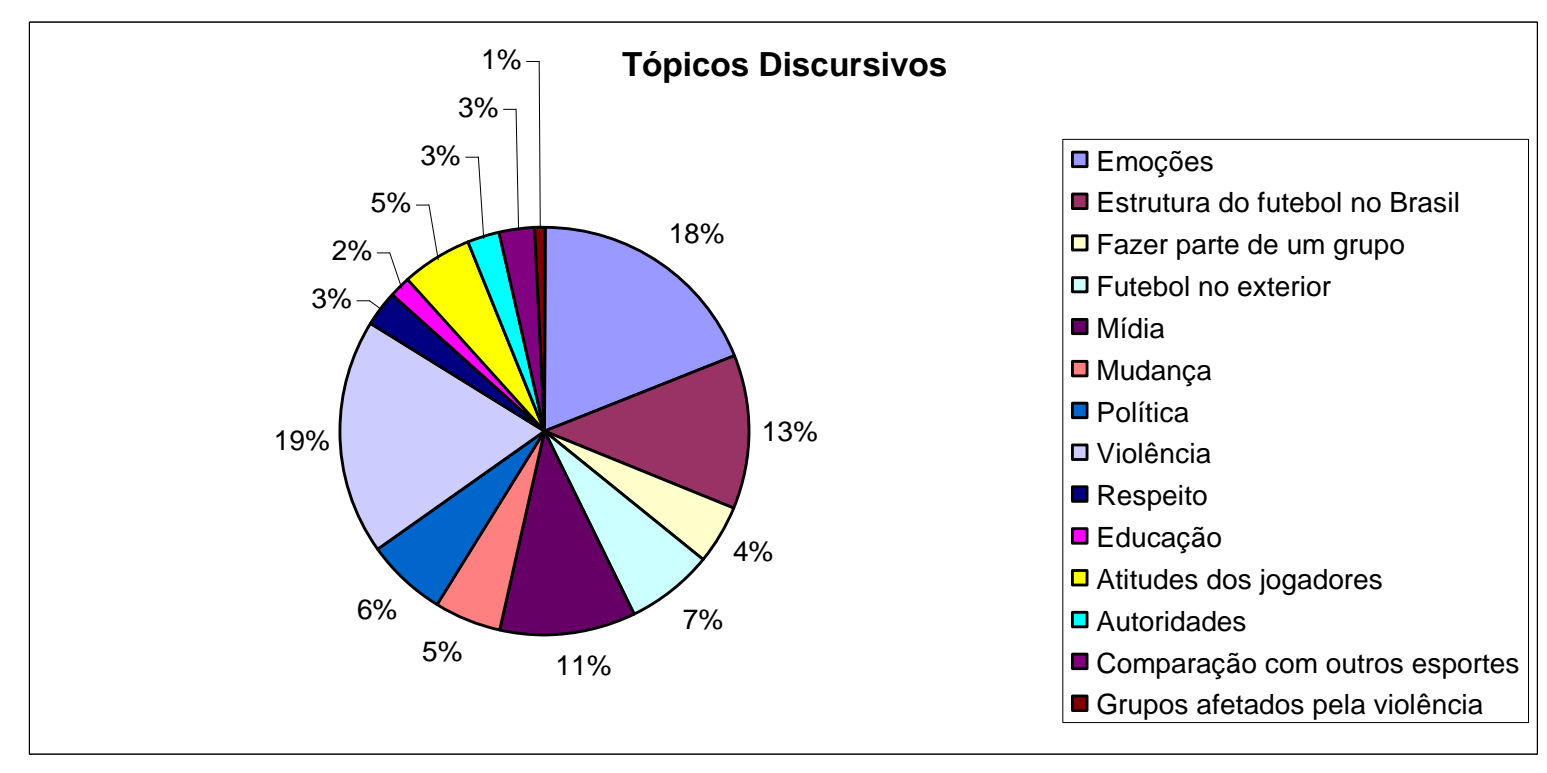

(FERREIRA, 2013)

Veja na sequência como esses Tópicos Discursivos (TDs) aparecem nos dados de uma maneira recorrente, motivando metáforas discursivas:

\section{Excerto 4:}

Toni: eu acredito que o futebol era pra ser

..um

..um esporte

..em que você pudesse assistir igual você assiste um jogo de tênis

..em que

..você pode levar seu filho,

você pode levar sua esposa

..e

..nós estamos caminhando pra que isso não aconteça mais 
No excerto 4, Toni veicula o Tópico Discursivo 'comparação com outros esportes' do quadro acima e vai utilizar um esquema imagético FONTE-CAMINHO-META para descrever a trajetória para onde a violência está nos conduzindo. Nesse caso, a violência está sendo conceitualizada nos dados como um CAMINHO com início que percorre uma trajetória e cujo objetivo é acabar com a liberdade do cidadão de se deslocar livremente. No excerto a seguir, foi constatado um uso metonímico.

\section{Excerto 5:}

Lívia: sou igual a ele, sou pessimista ..e tô achando cada vez mais que isso tende a piorar ..até mesmo ao ponto de chegar o time não jogar mais na casa, vir só os times adversários ..pra cá,

Maria: eu penso em não ir no estádio de futebol ...infelizmente

No excerto 5, por meio do Tópico Discursivo 'localização', foi identificado o veículo metonímico 'casa' que se repete nos dados sobre violência no futebol, já que 'jogar na casa' significa jogar 'no estádio do seu time' e é muito importante para o time por poder jogar com o apoio da sua torcida, ou seja, sentir-se seguro. Coincidentemente 'casa' significa metonimicamente 'segurança' nos dados sobre violência urbana no Brasil (FELTES; PELOSI; FERREIRA, 2012), e não poder jogar 'na casa' é descrito pela torcedora como um motivo de grande tristeza, pois jogar e vencer 'na casa', isto é, na sua sede, no seu estádio está associado com um grande valor simbólico para a torcida. No excerto 3, a participante revela seu temor em ir ao 'estádio', trata-se do temor do que pode vir a acontecer no que vem sendo denominado na mídia como 'o caminho do torcedor'. Nesses dois casos, foi detectado nos dados o que Cameron (2010) denominou de 'metáforas da paisagem social', isto é, um conjunto de metáforas espaciais utilizadas para conceitualizar as relações entre a sociedade e vários grupos sociais, principalmente metáforas que indicam 'PAISAGEM', 
'MOVIMENTO' E 'CONTÊINER' (p. 606). Tal cenário acessado por meio de tais metáforas possibilita o 'pensar-e-falar', à medida que as pessoas podem ajustar as suas concepções de como grupos sociais interagem. Segundo Cameron, isso está relacionado ao fato de diferentes grupos sociais geralmente ocuparem locais diferentes nas cidades. No caso dos dados de Cameron (2010), as comunidades de muçulmanos vivem restritas a uma determinada área de cidades industriais na Inglaterra e constituem uma comunidade homogênea. No caso dos dados do Brasil sobre metáfora e violência urbana, também se verificam referências a grupos sociais restritos a uma determinada área da cidade, como é o caso das favelas e aglomerados nas grandes cidades brasileiras, lugares que são referidos nos dados sobre violência urbana por meio do esquema imagético do 'CONTÊINER', em que temos a dicotomia 'rua'/ 'casa' e 'rua'/ 'estádio', sendo que os lugares fechados significam metonimicamente 'lugar seguro' e os lugares abertos onde, como a participante Clara fala a seguir, ocorre a 'batalha', significam 'perigo' para os torcedores. A seguir, veja como o 'medo', outro Tópico Discursivo que aparece nos dados sobre violência urbana no Brasil, em geral, é conceitualizado pela participante Clara.

Clara: O campo de batalha vai mudar, né.

Ricardo: [Uhum, vai sair da rua e],

Clara: ..naquele episódio que teve ali na frente do Chevrolet Hall, ...

Ricardo: os caras desceram pra brigar.. e um ${ }^{9}$ morreu.

Excerto 8:

Ricardo: ..no Mineirão,

dentro do estádio a segurança é muito efetiva, dá muito certo.

Veja, no excerto a seguir, como a participante Maria lamenta o fato de não poder 'vestir a camisa' do time. 'Vestir a camisa' pode ser interpretado literalmente, mas também tem um significado metafórico à medida que 'vestir a camisa' também significa 
para o torcedor a identificação com o time de futebol para o qual torce. Inclusive, a expressão metafórica 'vestir a camisa' é utilizada em outros contextos, como por exemplo o empresarial, quando queremos dizer que uma pessoa se identifica totalmente com uma proposta ou uma política, por exemplo na frase 'ela vestiu a camisa da empresa', a expressão 'vestir a camisa' significa que a funcionária é muito motivada e vai fazer todo o possível para beneficiar o seu empregador.

\section{Excerto 9:}

Maria: ..até em dias comuns a gente fica ..se perguntando <será que dá pra vestir a camisa do time, será que não dá> porque ..um torcedor ..muito fanático, no extremo do fanatismo, com certeza não vai se agradar de ver a gente com a-com do time oposto do dele

Nos excertos a seguir, resultantes da investigação de Silva (2013) sobre a experiência dos torcedores de Fortaleza sobre a sua ida ao estádio, verificamos o mesmo fenômeno: a palavra 'camisa' é utilizada primeiro literalmente (linha 33) e depois metonimicamente (I. 39) ao longo da fala do torcedor para referir emoções como medo e insegurança quando o torcedor fala na sua ida ao estádio para assistir a um jogo.

\section{Excerto 10:}

29.Carlos Eu sou uma pessoa que sou fanática pelo Ceará e tudo, eu vou pro estádio e eu gosto de ir no caminho do torcedor -

30. Alex $<X X>O$ cara ainda vai com medo ainda, vai com medo 31.Carlos Não sei o que vai acontecer - 
32.Alex $<X X>$ A pessoa vai assim, não sabe se volta, não sabe se volta.

33.Carlos Eu gosto de usar a camisa -

34. Alex Infelizmente tá assim.

35. Carlos Eu gosto de usar a camisa da torcida organizada, eu gosto

36. Carlos . Mas só que eu não me misturo com eles.

37. Antônio Dois

38. Carlos Mas se alguém me pegar vestido com aquela camisa na saída do estádio, na $<X X>$, sei lá.

39. Alex Aí o pessoal apanha por causa que tá usando a camisa, mesmo não sendo do -

Nesse sentido, os veículos metafóricos e os metonímicos vão se readaptando recorrentemente no fluxo da interação discursiva, formando redes de metáforas e de metonímias semanticamente semelhantes entre si, conectadas aos também recorrentes tópicos 'medo', 'insegurança' e, sobretudo, ao macro-tópico em debate, ou seja, à 'violência no futebol' (SILVA, 2013). Tendo em vista essas ocorrências, o processamento da conceitualização da violência no futebol a partir da interação discursiva em análise estabilizou-se temporariamente como a seguinte metáfora sistemática proposta: VIOLÊNCIA NO FUTEBOL É UM AGENTE QUE LIMITA O DESLOCAMENTO DO TORCEDOR.

Verificou-se que tanto os participantes do grupo focal em Belo Horizonte como os participantes do grupo focal em Fortaleza (SILVA, 2013) conceitualizaram a violência no futebol como um AGENTE QUE LIMITA O DESLOCAMENTO DO TORCEDOR.

A seguir serão apresentadas algumas conclusões importantes do presente estudo.

\section{CONSIDERAÇÕES FINAIS}

Vimos, no presente artigo, como metáforas e metonímias sistemáticas são utilizadas pelos participantes de um grupo focal em Belo Horizonte, a fim de discutir a sua experiência e expressar suas emoções como vítimas diretas e indiretas de violência 
no futebol. Um participante do grupo focal recorre à metonímia sistemática camisa para descrever como as pessoas procuram disfarçar a sua condição de torcedor para evitar despertar a atenção do agente da violência (FERREIRA; SILVA, a sair). Também constatamos esquemas imagéticos que descrevem a progressão do crescimento da violência no futebol nos últimos anos no Brasil, o que de certa forma confirma, na fala dos participantes, os dados apresentados por Murad (2012).

Vimos, portanto, como metáforas e metonímias sistemáticas são utilizadas numa interação por participantes de um grupo focal ao discutir sobre sua experiência e suas emoções com relação à violência no futebol vivenciadas na cidade de Belo Horizonte. Constatamos, como observou Cameron (2010), que metáforas e metonímias sistemáticas não são exclusivas de um único evento discursivo, como pudemos verificar nos dados do grupo focal do presente estudo, sobre violência no futebol em Belo Horizonte.

\section{NOTAS}

${ }^{1}$ Programa de Pós-Graduação em Estudos Lingüísticos, Universidade Federal de Minas Gerais, email: lucianeufmg@gmail.com

${ }^{2}$ DVD Penta - a hegemonia do Flamengo, 2009.

${ }^{3}$ Cf. Cameron (2010), metáforas sistemáticas devem aparecer em caixa alta e itálico, a fim de diferenciálas da metáfora conceitual.

${ }^{4}$ http://www.hojeemdia.com.br/minas/membros-da-galoucura-s-o-condenados-por-morte-de-cruzeirense1.85572

${ }^{5}$ http://ultimosegundo.ig.com.br/goleirobruno/

${ }^{6}$ Grupo de Estudos da Metáfora na Linguagem e no Pensamento.

${ }^{7}$ Houve duas coletas de dados anteriores em 2012, uma anterior (9.035 palavras) com oito participantes também sobre violência no futebol.

${ }^{8}$ Projeto aprovado pelo Comitê de Ética em Pesquisa (COEP) da UFMG em 2011.

${ }^{9}$ Aqui está implícita a palavra 'torcedor', pois um jovem torcedor do Cruzeiro foi assassinado a pauladas. A imagem do seu corpo estendido no meio da rua apareceu na mídia televisiva em todo o Brasil. 


\section{METAPHOR, FOOTBALL AND VIOLENCE IN MINAS GERAIS, BRAZIL}

\section{ABSTRACT}

This paper presents metaphorical as well as metonymical language which emerged in discursive interactions among participants when they talked about violence and soccer in Minas Gerais, Brazil. We take a discourse dynamics approach to metaphor that holds that the metaphors people use in talk reflect their emotions, values and understandings. The analysis is focussed on data gathered from the discourse produced by a focus group discussion in Belo Horizonte, Minas Gerais, Brazil. Our research question is how do participants use figurative language when they talk about violence and soccer? We adopted metaphor-led discourse analysis (CAMERON et al., 2009), which enables us to reflect on the way how Brazilians face situations of violence related to soccer and the figurative language they use in order to conceptualize violence.

Keywords: Urban Violence. Football. Figurative Language. Metaphor.

\section{REFERÊNCIAS}

CAMERON, L. Metaphors in educational discourse. London: Continuum, 2003.

CAMERON, L. Responding to the risk of terrorism: the contribution of metaphor. DELTA [online]. 2010, v. 26, n. Esp, p. 587-614. Disponível em :

<http://www.scielo.br/pdf/delta/v26nspe/v26nspe10.pdf>. Acesso em: 02 nov. 2013.

CAMERON, L. Metaphor shifting in the dynamics of talk. In: ZANOTTO, M.;

CAMERON, L.; CAVALCANTI, M. (Org.). Confronting metaphor in use: an applied linguistic approach. Amsterdam: John Benjamins Publishing Company, 2008. p. 45-62.

CAMERON, L.; MASLEN, R. Metaphor analysis: research practice in applied linguistics, social sciences and the humanities. UK: Equinox Publishing Ltd, 2010.

CAMERON, L. et al. The discourse dynamics approach to metaphor and metaphor-led discourse analysis. Metaphor and Symbol, 24(2), 2009, p. 63-89.

ELIAS, N. O processo civilizador. Rio de janeiro: Zahar, 1994. v. 1. 
FELTES, H. P. M. Semântica cognitiva: ilhas, pontes e teias. Porto Alegre: Edipucrs, 2007.

FERREIRA, L. C. Social status, metaphor and discourse about urban violence in Belo Horizonte, Brazil. [em revisão para publicação]

. Metáfora e futebol na mídia das Gerais. (submetido)

. O discurso sobre futebol e violência em Minas Gerais. Caderno de resumos:

Simpósio Metáfora e Violência. In: Conferência Linguística e Cognição, 5ํ, 2013, Santa Cruz do Sul: UNISC, 2013. Comunicação oral.

177.

. A conceitualização de violência e futebol. ANTARES, v. 4, n. 7, 2012, p, 166-

FERREIRA, L.C.; SILVA, P.H.S. O discurso sobre futebol e violência em Minas Gerais. Scripta, v. 18, n. 34, 2014. (aceito para publicação).

FERREIRA, L.C.; GONÇALVES, B.L. Football and metaphor. IV Congress on Metaphor in Language and Thought. UFRGS, Porto Alegre, 2011. Comunicação oral.

GRADY, J. Foundations of meaning: primary metaphors and primary scenes. Ph.D. thesis, UC Berkeley, 1997.

JOHNSON, M. The body in the mind. Chicago, Chigago University Press, 1987.

MACEDO, A. C. P. Metáfora, cognição e cultura: um estudo sobre conceitualizações de violência urbana em Fortaleza-Ceará-Brasil. Projeto PIBIC. PPGL, UFC, Fortaleza, 2010.

MURAD, M. A violência no futebol. São Paulo: Saraiva, 2012.

.Violência e futebol. Rio de Janeiro: Fundação Getúlio Vargas, 2007.

PRAGGLEJAZ GROUP. MIP: A method for identifying metaphorically-used words in discourse. Metaphor and symbol, v. 1, n. 22, 2007.

SILVA, P. H. S. Emergência de Metonímias Sistemáticas na Interação Discursiva entre Torcedores Vítimas da Violência no Futebol. Dissertação (Programa de Pós-Graduação em Linguística)-Universidade Federal do Ceará, Fortaleza, 2013.

SIMÓ, J. Chess metaphors in American English and Hungarian. Metaphor and symbol, v. 24, n. 1, 2008. 